\title{
The Role of Quality of Life Instruments in Obesity Management: Review
}

\author{
AU1 Roberto Accardi, RN, MSc, PhD, ${ }^{1}$ Antonella Delle Fave, Silvia Ronchi, RN, MSc, Stefano Terzoni, RN, PhD, \\ AU2 \\ Emanuela Racaniello, RN, MSc, and Anne Destrebecq, RN, $\mathrm{MSc}^{4}$
}

Background and Scope: Obesity represents a public health concern worldwide; it is associated with a high mortality risk and impairment in quality of life (QoL). Relationship between weight loss and QoL improvements was highlighted by several studies. This article aims to summarize the literature investigating QoL among obese persons. Attention will be paid to studies assessing QoL among obese patients undergoing bariatric surgery before and after surgical treatment and to the related measurement instruments.

Methods: A literature review was conducted on the major biomedical databases.

Results: Compared with general population, persons with obesity report lower QoL levels in most life domains. The global QoL improvement reported in all domains after bariatric surgery can be related to weight loss and its long-term stability. Although several tools were developed to assess QoL in obese persons, they are not suited to capture the needs of people with obesity. The promising results obtained through the Laval Questionnaire suggest the importance of expanding this research domain, to identify the best assessment tools for use in clinical practice.

Conclusion: The longitudinal assessment of the different QoL components can be useful to monitor the changes induced by the treatment over time.

Keywords: obesity, quality of life, morbid obesity, bariatric surgery, measurement

\section{Introduction}

O BESITY IS A MULTIFACTORIAL disease, due to an imbalance between caloric intake and energy expenditure, resulting in accumulation of excess calories in the form of triglycerides in adipose tissue deposits. ${ }^{1}$ Its etiology includes the copresence of genetic, metabolic, hormonal, psychological, and social factors, all influencing the clinical features of this condition. ${ }^{2}$ At the clinical level, it is identified as the presence of a body mass index (BMI) greater than $30 \mathrm{~kg} / \mathrm{m}^{2}$. Obesity represents a major problem for global health, as it is associated with a significant increase in morbidity and mortality and with the onset of disabilities that seriously undermine the person's quality of life (QoL). ${ }^{3,4}$ Impairment in QoL has been acknowledged as one of the most important negative consequences of obesity.

In 1995, the World Health Organization defined QoL as the "individuals' perception of their position in life in the context of the culture and value systems in which they live and in relation to their goals, expectations, standards, and concerns." ${ }^{2}$ Health related quality of life (HRQoL) instead refers to the overall effects of medical conditions on physical, mental, and social functioning and well-being, as subjectively perceived by the patient. ${ }^{6,7}$ It reflects the overall individual's subjective evaluation and reaction to health and illness. $^{8}$

The assessment of QoL levels includes the evaluation of the person's ability to autonomously perform daily activities, such as wearing socks and shoes or holding children. These routine tasks become difficult with obesity. Besides concerns related to health and aesthetic appearance, poor daily functioning - at the physical, psychological, and social levels-leads obese people to seek an effective and remedial action to solve the problem. QoL improvement has thus become an increasingly important target in clinical research and intervention, representing a core dimension to evaluate the effectiveness of healthcare services and practice. . $^{2,7,9,10}$ Weight loss reduces the risk of developing diseases ${ }^{4}$ and it is associated with positive changes in perceived HRQoL levels. A number of international and national organizations, such as the American Obesity Association, the Association of North America for the Study of Obesity, the European Association 
for the Study of Obesity, and the Società Italiana per lo Studio dell'Obesità (SICOB), consider QoL promotion as one of the primary goals of obesity treatment in adulthood. ${ }^{11-14}$ Several strategies have been developed to achieve this goal, such as behavioral therapy, dietary regimen, and pharmacological treatment. However, the long-term success rates of these strategies are unsatisfactory, as obese persons often experience great difficulty or even inability to achieve and/or maintain adequate weight. ${ }^{15}$ Surgical approaches like bariatric surgery ${ }^{16}$ are more effective in promoting weight reduction and comorbidities associated with obesity.

This article aims to summarize the literature addressing the relationship between obesity and QoL before and after weight loss programs and treatments. Furthermore, attention will be paid to the assessment instruments prominently used to evaluate QoL among obese people.

\section{Materials and Methods}

A narrative review of the literature published in the last 10 years was conducted on PubMed, CINAHL, and PsycINFO. To obtain a global overview of the state of the art in this domain, all types of study designs were included.

A first search was conducted with the keywords "obesity," "comorbidity," "quality of life," "assessment," "survey," and "treatment outcome" using both simple search and the database thesaurus, when available. A total of 149 articles were selected after duplicate removal and exclusion of nonpertinent articles. All the articles were reviewed by three different researchers and further checked by two additional ones. Among them, 68 publications were included; they reported the results of original studies, studies on epidemiological data, reviews, or clinical guidelines. According to the study design, they were evaluated through the CONSORT checklist (clinical trials) or the STROBE checklist (observational studies).

In addition, some studies on QoL related to selected article and published before 2005 were taken into consideration.

To classify the article contents according to criteria of comparability and homogeneity, we took into account the following dimensions: study outcomes, design, and inclusion/

T1 exclusion criteria. Table 1 summarizes the typology and main topic of the selected articles.

\section{Results}

\section{Obesity and QoL/HRQoL}

Persons with morbid obesity show impairments in all the domains of QoL and HRQoL compared to the general population. ${ }^{11,17}$

The most significant impairments of QoL and HRQoL levels are reported by morbid obese patients seeking bariatric surgical therapy for weight loss, ${ }^{7,18}$ especially as regards the physical variables. ${ }^{19,20}$ Several studies have identified an inverse correlation between BMI and HRQoL. ${ }^{12,19-21} \mathrm{Im}-$ paired physical aspects include overall health, physical symptoms, as well as limitations in daily life activities. ${ }^{21-23}$

Pain emerged as an important comorbidity condition associated with significant impairments in HRQoL among obese people. ${ }^{19,21,22}$ Problems and limitations related to the body size are reported to negatively impact on sexual life. ${ }^{24}$ Several studies highlighted that weight-related chronic

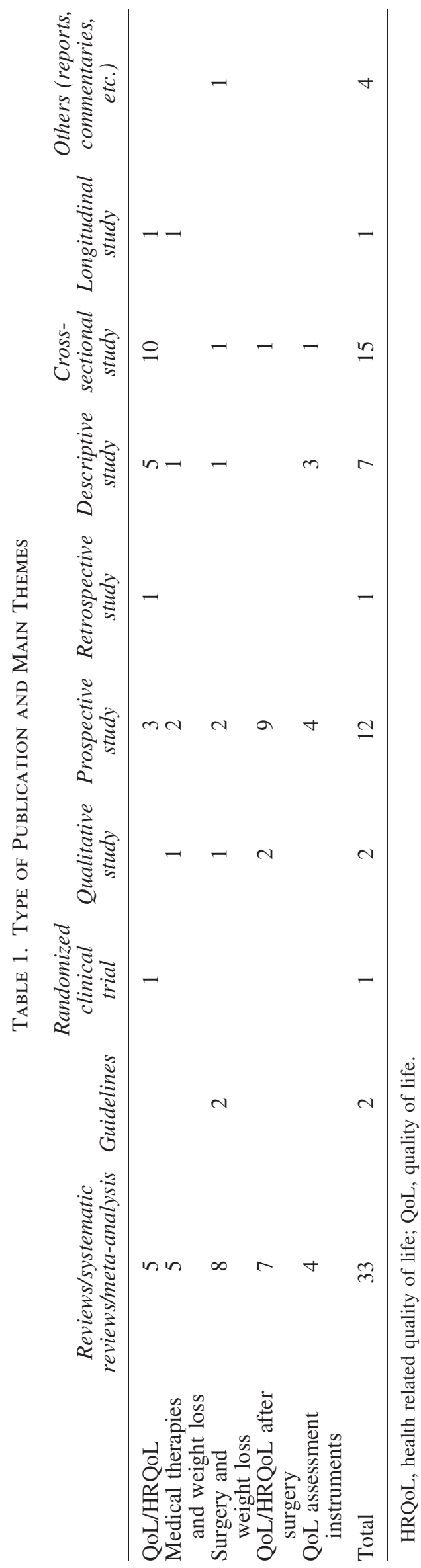


diseases contribute to a further lowering of $\mathrm{HRQOL}^{25}$ : people with multiple diseases report higher levels of psychological distress. ${ }^{26}$ The interaction between obesity and preexisting comorbidities, especially diabetes and hypertension, has a negative impact on HRQoL as well, as obesity further exacerbates the negative consequences of these other diseases. $^{27}$

Although the deterioration of QoL/HRQoL is more evident in the physical domain, ${ }^{20}$ individuals suffering from morbid obesity, especially those seeking for surgical therapy, also show impairments in the psychological domain. ${ }^{18,28}$ The limitations in daily activities due to persistent health problems are associated with indicators of psychological discomfort, such as low self-esteem, self-loathing, dissatisfaction with one's body, tendency to social isolation, sense of embarrassment or shame, and low self-efficacy beliefs regarding the ability to control food intake and the development of related comorbidities. ${ }^{18,23}$ In addition, obesity is often complicated by the presence of depression. ${ }^{21,29}$ The person's daily functioning is further impaired by role limitations due to emotional problems. ${ }^{21}$ In particular, obese individuals often experience and perceive discrimination, stigmatization, and prejudice, ${ }^{21,23}$ which can lead to difficulties in the social, family, and work roles and activities. ${ }^{2,10,24,30}$ These problematic aspects are associated with lower values of weightrelated QoL and more depressive symptoms, ${ }^{10}$ and they may lead to poor clinical outcomes. ${ }^{31}$

In particular, as concerns the social and working roles, obesity implies higher loss of working days for health reasons, reported drop of productivity, and perceived discrimination at the workplace. These psychological and social problems can trigger a vicious circle, leading to further weight increase. $^{28}$

Among the demographic factors influencing HRQoL perception among obese people, gender is especially relevant. ${ }^{17,32,33}$ Obese women report a poorer HRQoL not only compared to the general population but also compared to obese men, in both the physical and psychological dimensions. ${ }^{7,25}$ This finding can be related to the global impairment in the psycho-emotional sphere of HRQoL observed among female participants. ${ }^{26,33}$ In particular, obese women report lower self-esteem ${ }^{34}$ and more dissatisfaction with their physical appearance than men. ${ }^{17}$ In addition, they report higher social and emotional distress and a higher level of discomfort in public life activities. ${ }^{34,35}$

The relationship between HRQoL and body weight is also at least partially age dependent, as age is associated with the occurrence of comorbidities. $^{28}$

With regard to mental health components, a multicentric study conducted in Norway ${ }^{36}$ showed that self-esteem, sense of coherence, and adaptive coping strategies substantially contribute to the improvement of HRQoL among men and women seeking treatment for morbid obesity. The same study suggested that younger age, having a paid activity, and being physically active explain better outcomes in the physical domain. ${ }^{36}$ Other studies highlighted the positive role of work, both in relation to HRQoL in general and to its mental and physical components. ${ }^{35,37}$ Instead, no relationship emerged between HRQoL and the level of education, marital status, and use of alcohol or drugs. ${ }^{37}$

The mental component of HRQoL is also influenced by the presence of eating disorders ${ }^{7}$ : obese women with binge eating syndrome or night eating syndrome report a poorer general health, in both the physical and mental dimensions. ${ }^{38}$

\section{Obesity and weight loss: medical and surgical therapies}

The benefits of weight loss include lower risk of developing comorbidity, ${ }^{4}$ but also an improvement in HRQoL levels. ${ }^{12,13}$ A qualitative study highlighted that obese people associate weight loss with getting healthy, acting normally in one's roles, discovering a new sense of identity, fitting in socially, relating differently with other people at work, at home, and in society, and eating to improve health. ${ }^{39}$ In addition, weight loss is associated with substantial improvements in energy levels and ability to perform daily activities. ${ }^{40}$ HRQoL improves significantly even when the weight loss is modest, and the benefits that can be derived from a consistent weight loss may persist for several years. ${ }^{8}$

Physical activity and diet represent the first step in obesity treatment, and they were shown to have a positive impact on HRQoL through the reduction of body weight. ${ }^{40}$ Programs of weight management, organized by specialized medical structures $^{41}$ or supported by mobile technology, are useful in terms of cost benefit and are reasonably successful in adults with a BMI between 25 and $39.9 \mathrm{~kg} / \mathrm{m}^{2}$. ${ }^{42}$ They may include diet therapy, physical activity, and behavioral therapy. Pharmacotherapy may be added, when the other strategies alone are not effective. ${ }^{16}$

In obese patients weight loss can be obtained through pharmacological treatment associated with lifestyle changes. Nevertheless, behavioral therapy, diet, and pharmacological treatment are often insufficient: many obese people do not manage to achieve satisfactory weight loss or to maintain the optimal weight over time with diet and exercise only. ${ }^{15}$

Surgical interventions like bariatric therapy have longterm success in the majority of patients, leading to the loss of $60-70 \%$ excess weight, defined as the difference between present and ideal weight. ${ }^{43}$ Bariatric surgery is a safe and effective treatment providing significant and sustained weight loss. ${ }^{15,16,44-47}$ It also proved to be more effective than the other intervention strategies in treating or preventing obesity-related comorbidity, ${ }^{47,48}$ thus representing the treatment of choice when diet and exercise failed to produce consistent results. ${ }^{24,49}$

In patients with extreme obesity (BMI $>40 \mathrm{~kg} / \mathrm{m}^{2}$ ) bariatric surgery allows to achieve three main goals as follows: weight loss, reduction of medical risk factors, and improvement of QoL. ${ }^{18}$ Compared to dietary treatment, surgery is associated with significantly better management of obesity-related comorbidities and higher HRQoL. In patients with a BMI $>35 \mathrm{~kg} / \mathrm{m}^{2}$ it also reduces mortality by decreasing cardiovascular risk. $^{48}$

According to the guidelines of the Association of Clinical Endocrinologists, the Obesity Society, the American Society for Metabolic \& Bariatric Surgery, and the European Association for the study of Obesity, bariatric surgery can only be offered to obese persons who present (a) a BMI $\geq 40$ without high surgical risk and (b) a BMI $\geq 35$ with obesity-related comorbidities. ${ }^{14,16,50,51}$

Surgery may be also offered to patients with a BMI between 30 and 34.9 associated with diabetes or metabolic syndrome, but evidence of long-term benefits is lacking for 
this population. Regardless of BMI values, bariatric surgery is not recommended for the control of comorbidities alone, like glycemic control, lipid lowering, or cardiovascular disease risk reduction. ${ }^{50}$

Bariatric surgery ultimately operates through the lowering of caloric intake. This goal is achieved by limiting the amount of food the stomach can hold through the reduction of the organ size or through the reduction of calories that can be absorbed from the gastrointestinal tract. The most common surgical procedures are gastric bypass, adjustable gastric banding, biliopancreatic diversion with duodenal switch, and sleeve gastrectomy. ${ }^{15}$ The choice of the type of surgery depends on treatment goals, surgeon's skills, patient's preferences, and individual surgical risk. Overall, whenever possible, a laparoscopic procedure is recommended. ${ }^{50}$

Although very effective in reducing weight and comorbidities associated with obesity, bariatric surgery is not widely practiced for different reasons, ranging from the lack of surgical manpower and qualified centers to the lack of a sufficiently large amount of evidence as concerns stratification of risk factors, identification of the optimal intervention for each patient, comparison of procedures, planning of care paths, and assessment of long-term outcomes. Issues related to surgery costs and malpractice exposure remain to be solved as well. ${ }^{52}$ As a result, less than $1 \%$ of the patients who could benefit from this kind of intervention have access to it. ${ }^{15,51,52}$

\section{QoL/HRQoL after surgical therapies}

The refractoriness in performing bariatric surgery contrasts with the positive outcomes observed in terms of HRQoL, regardless of the type of intervention. ${ }^{24}$ Several studies conducted on patients undergoing laparoscopic gastric banding detected rapid and highly significant improvements in HRQoL and QoL during the first year after surgery, ${ }^{6,53}$ up to levels comparable to those reported by the general healthy population. ${ }^{4,6,53}$ Patients previously experiencing a poorer HRQoL reported the most relevant benefits from the surgical procedure. ${ }^{6}$

The beneficial consequences of bariatric surgery on QoL occur primarily in the physical dimension, which shows improvements within 1 year $^{47}$ in relation to the physical changes following surgery. ${ }^{54,55}$ However, HRQoL improvement is proportional to weight loss if its baseline level was determined mainly by obesity-related physical factors, ${ }^{7}$ while no relationship was detected between preoperative comorbidities or the resolution of comorbidities after surgery and the magnitude of HRQoL improvements. ${ }^{6}$ Improvements in HRQoL after surgery were also detected in social and working life: the higher comfort reported in public places allows patients to become more socially active, to date, and have affairs. Patients followed after bariatric surgery were more active, required less medical care, and took fewer sick days. Weight loss attained through bariatric surgery also improves sexual life through the improvement of physical conditions and body image. ${ }^{24,56}$ Weight loss has also a positive impact on bodily pain. ${ }^{21}$

The psychological benefits of bariatric surgery include improvements in body image and perceived attractiveness, as well as lower levels of depression. ${ }^{44}$ However, even though surgery related changes allow the person to build a new and more positive self-concept, ${ }^{54}$ this process is slower and more difficult than the adaptation to physical and exterior chan- ges. ${ }^{39}$ Moreover, the improvements in HRQoL after surgery can be less relevant or temporary, if patients' poor preoperative HRQoL was due to mental disorders not corrected by weight loss. In particular, the persistence or recurrence of depression and/or eating disorders in the follow-up may attenuate the positive effects of bariatric surgery on HRQoL or induce a deterioration of HRQoL in the phase of weight stabilization, when the positive psychological effects of weight loss tend to vanish. ${ }^{7}$

Adopting Calman's conceptual model of QoL, HRQoL improvements after bariatric surgery, especially as concerns the psychological dimension, can be related to the fulfilment of expectations, ${ }^{57}$ whereas unmet expectations are likely to result in dissatisfaction. ${ }^{58}$ This claim was confirmed by the results of a study conducted among people with morbid obesity: showing a lower mental component summary score in the preoperative period was associated with high expectations about the emotional improvements obtainable by surgery. In the postoperative period, the fulfilment of preoperative expectations was associated with better mental HRQoL 5 years after surgery. ${ }^{59}$ Overall, positive and realistic expectations are predictors of the best results in terms of weight loss after surgery, especially in combination with a strong sense of self-confidence. ${ }^{60}$ The role of expectations and motivations regarding the successful outcome of surgery is also reported in the systematic review by Van Hout et al., reporting that the expectations of patients regarding the operation influence short-term and long-term consequences. These authors also underline that two aspects are important in this process: expectations concerning the person's own share in the results and the degree of reality of these expectations. ${ }^{2}$

The review of Msika and Castel identified some predisposing factors for the success of bariatric surgery in terms of weight loss. ${ }^{61}$ According to these researchers, demographic features play a relevant role in predicting surgery outcomes. As concerns age, weight loss is better in younger participants, and it is related to the lower presence of comorbidity and the better mobility characterizing these patients compared with other ones. Gender did not emerge as a predictor of the intervention's success, whereas socioeconomic status seems to play a more influential role. In particular, individuals with lower income get poorer outcomes and increased postoperative complications. Preoperative weight and BMI also influence the surgery success, while eating disorders are usually related to worse postoperative outcomes. ${ }^{61}$ The relationship between treatment outcomes and factors related to personality and psychopathology is still controversial, and results from different studies are conflicting. ${ }^{2,61}$ However, postoperative complications were detected among patients who had developed obesity after exposure to traumatic events during childhood or adolescence. ${ }^{62}$

\section{QoL assessment instruments in obese patients}

As improvement in QoL represents one of the core aims of bariatric surgery, the assessment of patients' HRQoL is relevant for designing clinical care planning and for evaluating the intervention's success. In addition, the assessment of patients' perceived HRQoL may provide information about the outcome expected from therapies in terms of weight loss: it has been shown that patients with the most impaired levels of general HRQoL at baseline have the greater improvements 
of HRQoL after surgery ${ }^{6}$; in particular, those who report low mental well-being, but not low scores on the physical dimension, get a better long-term outcome of weight loss.

On the contrary, Teixeira et al. underline that, from the studies conducted on behavioral management of obesity, women reporting lower HRQoL in the areas of work, health, and self-esteem at the beginning of interventions were more likely to be included among the least successful. ${ }^{60}$

Therefore, the perception of HRQoL can be predictive of outcomes in the short and long term, depending on the type of therapy chosen to treat obesity.

A variety of more or less specific instruments have been used to assess HRQoL in populations of obese persons. ${ }^{8}$

Table 2 summarized advantages and weaknesses of some of the most used questionnaires for QoL assessment in obese subjects (Table 2). Disease-specific instruments are usually more sensitive to changes occurring during treatment, as they focus on the domains of HRQoL that are more affected by the disease and whose improvement may thus be more relevant for the examined population. ${ }^{63,64}$

Instruments measuring the perceived impact of obesity on health include items focusing on physical health, at the same time assessing the impact of disease on the level of functioning in daily life domains not related to health. Within this category, the widely used Impact of Weight on Quality of Life (IWQOL)-Lite tool measures the perceived impact of weight on physical functioning and somatic sensations such as pain and distress. ${ }^{13}$ IWQOL-Lite shows a good content validity ${ }^{13,65}$ and effectiveness in detecting the changes in HRQoL associated with short-term treatments. ${ }^{66}$

In the studies conducted by the Italian Group for LapBand, HRQoL of obese participants is predominantly assessed through SF-36, ${ }^{6,7}$ and less frequently through the Obesity-Related Well-being (ORWELL 97) scale, which comprises 18 items investigating the physical dimension along with the symptoms related to BMI, without considering the psychosocial aspects. ${ }^{8}$

The development and use of valid obesity-specific measures are important to advance evidence-based practice within the rapidly evolving field of disease management. ${ }^{13} \mathrm{~A}$ review conducted by the Canadian research team of the Laval Hospital identified that only three of them were suited for a population with morbid obesity and all presented some flaws. ${ }^{66}$ These results pointed to the need for a specific

Table 2. Most Common Quality of Life Instruments in Available Literature: Advantages and Weakness

\begin{tabular}{|c|c|c|c|}
\hline Instrument & Type & Advantages & Disadvantages \\
\hline SF-36 & Generic & $\begin{array}{l}\text { Possibility of comparing QoL of obese } \\
\text { subjects with QoL of patients with } \\
\text { different chronic illness. } \\
\text { Presence of a validated SF-12. }\end{array}$ & $\begin{array}{l}\text { Not useful in assessing disorders and } \\
\text { discomforts closely related to obesity }\end{array}$ \\
\hline EQ-5D & Generic & $\begin{array}{l}\text { Possibility of performing cost-utility } \\
\text { analysis using QALY as an outcome. } \\
\text { Brief and easy to fill. }\end{array}$ & $\begin{array}{l}\text { More focused on physical dimension. } \\
\text { Not useful in assessing disorders and } \\
\text { discomforts closely related to obesity. }\end{array}$ \\
\hline $\begin{array}{l}\text { WHO-QOL } \\
\text { Brief }\end{array}$ & Generic & $\begin{array}{l}\text { Possibility of comparing QoL of obese } \\
\text { subjects with QoL of patients with } \\
\text { other pathologies. } \\
\text { Created on the basis of an international } \\
\text { project promoted and coordinated } \\
\text { by the WHO. }\end{array}$ & $\begin{array}{l}\text { Not useful in assessing disorders and } \\
\text { discomforts closely related to obesity }\end{array}$ \\
\hline IWQOL-Lite & Specific & $\begin{array}{l}\text { Specific to measure the perceived impact } \\
\text { of weight on physical functioning } \\
\text { and somatic sensations. }\end{array}$ & $\begin{array}{l}\text { It fails to assess gastrointestinal } \\
\text { symptoms which are common } \\
\text { after obesity surgery. }\end{array}$ \\
\hline ORWELL-97 & Specific & $\begin{array}{l}\text { Developed with the contributions } \\
\text { of several health professionals } \\
\text { and obese people. }\end{array}$ & $\begin{array}{l}\text { Poor consideration of the emotional } \\
\text { and psychological aspects of QoL. }\end{array}$ \\
\hline BQL Index & Specific & $\begin{array}{l}\text { Possibility to recollect many data, } \\
\text { including medical data on comorbidities, } \\
\text { side effects, and medications. } \\
\text { Short and easy; it can be applied before } \\
\text { and after surgery for good overall } \\
\text { sensitivity to change of the BQL }\end{array}$ & $\begin{array}{l}\text { Created on the basis of needs of } \\
\text { bariatric surgeons but lack of } \\
\text { consideration of patient's need. }\end{array}$ \\
\hline $\begin{array}{l}\text { Laval } \\
\quad \text { questionnaire }\end{array}$ & Specific & $\begin{array}{l}\text { Possibility to recollect many data, including } \\
\text { medical data on comorbidities, } \\
\text { side effects, and medications and data } \\
\text { related to emotional, psychological, } \\
\text { sexual, and social distress. } \\
\text { Specifically developed for use in } \\
\text { bariatric surgery. } \\
\text { Created on the basis of needs of } \\
\text { bariatric surgeons and patients. }\end{array}$ & $\begin{array}{l}\text { Not useful to make comparison in } \\
\text { QoL between obese subjects and } \\
\text { patients with different chronic } \\
\text { illnesses. } \\
\text { Not possible to make cost-utility } \\
\text { analysis. }\end{array}$ \\
\hline
\end{tabular}

BQL, bariatric quality of life; IWQOL, Impact of Weight on Quality of Life; ORWELL, Obesity-Related Well-being; QALY, qualityadjusted life year; SF, short-form. 
questionnaire evaluating the expectations and perceived postoperative outcomes of patients with morbid obesity. ${ }^{17}$ Based on this evidence, the Canadian researchers recruited 100 patients with morbid obesity, inviting them to rate on a five-point Likert scale the QoL related importance of a set of outcome variables. The 44 variables identified as most relevant to QoL became the items of the Laval Questionnaire, organized into six domains as follows: symptoms (10 items); activity/mobility (9 items); personal hygiene/clothing (5 items); emotions (11 items); social interactions ( 7 items); and sexual life (2 items). Patients are invited to reflect on how obesity affected their life over the last 4 weeks and to answer to each item accordingly. Items are rated on a seven-point Likert scale, with higher scores meaning better QoL. The questionnaire administration takes on average $10 \mathrm{~min}$ and the validation study, conducted in French, highlighted the instrument's validity as a measure of HRQoL, its sensitivity to changes induced by the treatment, and its specificity for patients with morbid obesity. The analysis of the discriminative function of the questionnaire showed moderate-to-high correlations between the scores in each domain of this new instrument and the corresponding "gold-standard" questionnaires. The analysis of its evaluative function showed significant differences in score changes between patients with bariatric surgery and those without and moderate-to-high correlations between the changes in scores in the new instrument and the changes in the corresponding questionnaires.

The Laval Questionnaire may thus represent a useful tool for research and clinical use. ${ }^{29}$ The strength of Laval questionnaire is its specificity for the use in the contexts of bariatric surgery: the Laval Questionnaire appears to be a very specific instrument for patients with morbid obesity who intend to undergo interventions of bariatric surgery. Because of its specificity, it wouldn't be useful to make comparison in QoL between obese subjects and patients with different chronic illness. Furthermore, it appears useless for making cost-utility analysis.

\section{Conclusions}

The incidence of obesity is constantly increasing worldwide ${ }^{67}$ Besides being an economic cost to health national systems, ${ }^{15}$ this disease represents a major risk factor for the onset of various comorbidities, ${ }^{68}$ and it exposes affected persons to impairments in physical, psychological, and social dimensions of QoL and HRQoL. ${ }^{11,17}$ Demographic and clinical factors such as BMI, ${ }^{21}$ female gender, ${ }^{32}$ unemployment, ${ }^{35}$ and the presence of comorbidity ${ }^{25}$ directly impact on QoL levels, together with psychological factors, such as coping style and self-esteem. ${ }^{36}$ In contrast, weight loss has a positive effect on all QoL and HRQoL components, which attain levels similar to those reported by healthy participants within 1 year after treatment. ${ }^{4,6}$ The assessment of QoL of obese people in the pretreatment period is essential, as the person's expectations regarding QoL improvements due to weight loss can influence treatment outcomes. ${ }^{6}$

Among the available treatments, bariatric surgery allows to achieve rapid and lasting weight $\operatorname{loss}^{15,46}$ and can be offered to patients with severe obesity. ${ }^{50}$ Like for the other therapeutic approaches, the improvement in QoL and HRQoL is one of the main purposes of surgical procedures. ${ }^{18}$ Therefore, patients' perceived HRQoL before surgery can be used to predict the results of the interventions in terms of weight loss. ${ }^{60}$ Moreover, the longitudinal assessment of the different QoL components can be useful to monitor the biological, psychological, and social changes induced by the treatment over time.

\section{Authors' Contribution}

All authors have made a substantial contribution to the selection, critical evaluation, and analysis of the literature. All authors participated in writing and revising the article.

\section{Author Disclosure Statement}

No competing financial interests exist.

\section{References}

1. American Association of Clinical Endocrinologist, the Obesity Society and American Society for Metabolic and Bariatric Surgery. Medical Guidelines for clinical practice for the preoperative nutritional, metabolic and non-surgical support of the bariatric surgery patient. Endocr Pract 2008; 14:1-83.

2. Van Hout GCM, Verschure SKM, van Heck GL. Psychosocial predictors of success following bariatric surgery. Obes Surg 2005; 15:552-560

3. Prentice P, Viner RM. Pubertal timing and adult obesity and cardiometabolic risk in women and men: a systematic review and meta-analysis. Int J Obes (Lond) 2013;37: 1036-1043.

4. Dixon JB, O'Brien PE. Changes in comorbidities and improvements in quality of life after LAP-BAND placement Am J Surg 2002;184:51S-54S.

5. The World Health Organization Quality of Life assessment (WHOQOL): position paper from the World Health Organization. Soc Sci Med 1995;41:1403-1409.

6. Pilone V, Mozzi E, Schettino AM, Furbetta F, Di Maro A, Giardiello C, et al. Improvement in health-related quality of life in first year after laparoscopic adjustable gastric banding. Surg Obes Relat Dis 2012;8:260-268

7. Busetto L, Pilone V, Schettino AM, Furbetta N, Zappa M, Di Maro A, et al. Determinants of health-related quality of life in morbid obese candidates to gastric banding. Eat Weight Disord 2012;17:e93-e100.

8. Kolotkin RL, Meter K, Williams GR. Quality of life and obesity. Obes Rev 2001;2:219-229.

9. Smith MC. Obesity as a social problem in the United States: application of the public arenas model. Policy Polit Nurs Pract 2009;10:134-142.

10. Sarwer DB, Fabricatore AN, Eisenberg MH, Sywulak LA Wadden TA. Self-reported stigmatization among candidates for bariatric surgery. Obesity (Silver Spring) 2008;16 Suppl 2:S75-S79.

11. Stucki A, Borchers M, Stucki G, Cieza A, Amann E, Ruof J. Content comparison of health status measures for obesity based on the international classification of functioning, disability and health. Int J Obes 2006;30:1791-1799.

12. Herman KM, Hopman WM, Craig CL. Are youth BMI and physical activity associated with better or worse than expected health-related quality of life in adulthood? The Physical Activity Longitudinal Study. Qual Life Res 2010; 19:339-349.

13. Forhan M, Vrkljan B, MacDermid J. A systematic review of the quality of psychometric evidence supporting the use of an 
obesity-specific quality of life measure for use with persons who have class III obesity. Obes Rev 2010;11:222-228.

14. Yumuk V, Tsigos C, Fried M, Schindler K, Busetto L, Micic D, et al. European Guidelines for obesity management in adults. Obes Facts 2015;8:402-424.

15. Ponstein L. Assessing the nurses' knowledge of bariatric surgery: a performance improvement project. Bariatr Nurs Surg Patient Care 2012;7:167-171.

16. Cannon CP, Kumar A. Treatment of overweight and obesity: lifestyle, pharmacologic, and surgical options. Clin Cornerstone 2009;9:55-68; discussion 69-71.

17. Duval K, Marceau P, Lescelleur O, Hould F-S, Marceau S, Biron $\mathrm{S}$, et al. Health-related quality of life in morbid obesity. Obes Surg 2006;16:574-579.

18. Nelbom B, Naver L, Ladelund S, Hornnes N. Patient characteristics associated with a successful weight loss after bariatric surgery. Bariatr Nurs Surg Patient Care 2010;5: 313-319.

19. Fontaine KR, Barofsky I. Obesity and health-related quality of life. Obes Rev 2001;2:173-182.

20. Renzaho A, Wooden M, Houng B. Associations between body mass index and health-related quality of life among Australian adults. Qual Life Res 2010;19:515-520.

21. Huang C-Y, Hsu M-C, Pan K-C, Huang C-K, Chi S-C. Early health status and health-related quality of life after laparoscopic gastric bypass surgery in morbidly obese patients. Bariatr Nurs Surg Patient Care 2011;6:193-200.

22. Brett Hauber A, Mohamed AF, Reed Johnson F, Oyelowo $\mathrm{O}$, Curtis BH, Coon C. Estimating importance weights for the IWQOL-Lite using conjoint analysis. Qual Life Res 2010;19:701-709.

23. Collins J, Meng C, Eng A. Psychological impact of severe obesity. Curr Obes Rep 2016;5:435-440.

24. Kent P. Lifestyle changes following bariatric surgery. Bariatr Nurs Surg Patient Care 2007;2:209-214.

25. Serrano-Aguilar P, Muñoz-Navarro SR, Ramallo-Fariña Y, Trujillo-Martín MM. Obesity and health related quality of life in the general adult population of the Canary Islands. Qual Life Res 2009;18:171-177.

26. Magallares A, Pais-Ribeiro JL. Mental health and obesity: a meta-analysis. Appl Res Quali Life 2014;9:295-308.

27. Sullivan PW, Ghushchyan VH, Ben-Joseph R. The impact of obesity on diabetes, hyperlipidemia and hypertension in the United States. Qual Life Res 2008;17:1063-1071.

28. Cameron AJ, Magliano DJ, Dunstan DW, Zimmet PZ, Hesketh K, Peeters A, et al. A bi-directional relationship between obesity and health-related quality of life: evidence from the longitudinal AusDiab study. Int J Obes 2012;36: 295-303.

29. Therrien F, Marceau P, Turgeon N, Biron S, Richard D, Lacasse Y. The laval questionnaire: a new instrument to measure quality of life in morbid obesity. Health Qual Life Outcomes 2011;9:66.

30. Lee DW, Kim S, Cho DY. Obesity-related quality of life and distorted self-body image in adults. Appl Res Qual Life 2013;8:87-100.

31. Falker AJ, Sledge JA. Utilizing a bariatric sensitivity educational module to decrease bariatric stigmatization by healthcare professionals. Bariatr Nurs Surg Patient Care 2011; 6:73-78.

32. Bentley TGK, Palta M, Paulsen AJ, Cherepanov D, Dunham NC, Feeny D, et al. Race and gender associations between obesity and nine health-related quality-of-life measures. Qual Life Res 2011;20:665-674.
33. Kolotkin RL, Crosby RD, Kosloski KD, Williams GR. Development of a brief measure to assess quality of life in obesity. Obes Res 2001;9:102-111.

34. Tessier A, Zavorsky GS, Kim DJ, Carli F, Christou N, Mayo NE. Understanding the determinants of weight-related quality of life among bariatric surgery candidates. J Obes 2012;2012:1-9.

35. Lund RS, Karlsen T-I, Hofsø D, Fredheim JM, Røislien J, Sandbu R, et al. Employment is associated with the healthrelated quality of life of morbidly obese persons. Obes Surg 2011;21:1704-1709.

36. Lerdal A, Andenæs R, Bjørnsborg E, Bonsaksen T, Borge L, Christiansen B, et al. Personal factors associated with health-related quality of life in persons with morbid obesity on treatment waiting lists in Norway. Qual Life Res 2011; 20:1187-1196.

37. Vetter ML, Wadden TA, Lavenberg J, Moore RH, Volger $\mathrm{S}$, Perez JL, et al. Relation of health-related quality of life to metabolic syndrome, obesity, depression and comorbid illnesses. Int J Obes (Lond) 2011;35:1087-1094.

38. Silva IL, Pais-Ribeiro J, Cardoso H. Quality of life and general health perception in women with obesity: do eating patterns make a difference? Appl Res Qual Life 2008;3: $127-136$.

39. Stolzenberger KM, Meaney CA, Marteka P, Korpak S, Morello K. Long-term quality of life following bariatric surgery: a descriptive study. Bariatr Surg Patient Care 2013; 8:29-38.

40. Fontaine KR, Barofsky I, Andersen RE, Bartlett SJ, Wiersema L, Cheskin LJ, et al. Impact of weight loss on health-related quality of life. Qual Life Res 1999;8:275277.

41. Rothberg AE, McEwen LN, Fraser T, Burant CF, Herman $\mathrm{WH}$. The impact of a managed care obesity intervention on clinical outcomes and costs: a prospective observational study: managed care obesity intervention. Obesity 2013;21: 2157-2162.

42. Bacigalupo R, Cudd P, Littlewood C, Bissell P, Hawley MS, Buckley Woods H. Interventions employing mobile technology for overweight and obesity: an early systematic review of randomized controlled trials: early systematic review of mobile technology for obesity. Obes Rev 2013; 14:279-291.

43. Goldman RL, Canterberry M, Borckardt JJ, Madan A, Byrne TK, George MS, et al. Executive control circuitry differentiates degree of success in weight loss following gastric-bypass surgery: brain activation post gastric-bypass. Obesity 2013;21:2189-2196.

44. Pfeil M, Pulford A, Mahon D, Ferguson Y, Lewis MP. The patient journey to gastric band surgery: a qualitative exploration. Bariatr Surg Pract Patient Care 2013;8:69-76.

45. Rowen, L. Overview and summary: obesity on the rise: what can nurses do? OJIN 2009;14:Overview.

46. Neff KJH, le Roux CW. Bariatric surgery: a best practice article. J Clin Pathol 2013;66:90-98.

47. Zijlstra H, Larsen JK, Wouters EJM, van Ramshorst B, Geenen R. The long-term course of quality of life and the prediction of weight outcome after laparoscopic adjustable gastric banding: a prospective study. Bariatr Surg Patient Care 2013;8:18-22.

48. Leff DR, Heath D. Surgery for obesity in adulthood. BMJ 2009;339:b3402-b3402.

49. Clegg A, Colquitt J, Sidhu M, Royle P, Walker A. Clinical and cost effectiveness of surgery for morbid obesity: a 
systematic review and economic evaluation. Int $\mathrm{J}$ Obes 2003;27:1167-1177.

50. Mechanick JI, Youdim A, Jones DB, Garvey WT, Hurley DL, McMahon MM, et al. Clinical practice guidelines for the perioperative nutritional, metabolic, and nonsurgical support of the bariatric surgery patient-2013 update: cosponsored by American Association of Clinical Endocrinologists, the Obesity Society, and American Society for Metabolic \& Bariatric Obesity 2013;21(S1):S1-S27.

51. Muoneke PU, Idzik SR. Nutritional resources for postbariatric surgery patients and healthcare workers. Bariatr Nurs Surg Patient Care 2011;6:99-102.

52. Pories WJ, Pratt GM. Quality control of bariatric surgery. Bariatr Nurs Surg Patient Care 2006;1:53-59.

53. Accardi R, Lattuada E, Racaniello E, Ronchi S, Terzoni S, Destrebecq A. Different quality of life outcomes between Roux-en-Y gastric bypass and laparoscopic adjustable gastric banding. Bariatr Surg Pract Patient Care 2017; 12:29-34.

54. Sutton D, Raines DA. Perception of health and quality of life after bariatric surgery. Bariatr Nurs Surg Patient Care 2007;2:193-198.

55. Malone M, Alger-Mayer S, Polimeni JM. Health related quality of life after gastric bypass surgery. Appl Res Qual Life 2012;7:155-161.

56. Song P, Patel NB, Gunther S, Li C-S, Liu Y, Lee CYG, et al. Body image \& quality of life: changes with gastric bypass and body contouring. Ann Plast Surg 2016;76 Suppl 3:S216-S221.

57. Pristed SG, Omar HK, Kroustrup JP. Association between fulfilment of expectations and health-related quality of life after gastric bypass. Appl Res Qual Life 2013;8:101-111.

58. Carr AJ, Gibson B, Robinson PG. Measuring quality of life: is quality of life determined by expectations or experience? BMJ 2001;322:1240-1243.

59. Pristed SG, Fromholt J, Kroustrup JP. Relationship between morbidly obese subjects' attributions of low general wellbeing, expectations and health-related quality of life: fiveyear follow-up after gastric banding. Appl Res Qual Life 2012;7:281-294.
60. Teixeira PJ, Going SB, Sardinha LB, Lohman TG. A review of psychosocial pre-treatment predictors of weight control. Obes Rev 2005;6:43-65.

61. Msika S, Castel B. Present indications for surgical treatment of morbid obesity: how to choose the best operation? J Visc Surg 2010;147:e47-e51.

62. Faden J, Leonard D, O'Reardon J, Hanson R. Obesity as a defense mechanism. Int J Surg Case Rep 2013;4:127-129.

63. Kolotkin RL, Crosby RD. Psychometric evaluation of the impact of weight on quality of life-lite questionnaire (IWQOLlite) in a community sample. Qual Life Res 2002;11:157-171.

64. Kolotkin RL, Norquist JM, Crosby RD, Suryawanshi S, Teixeira PJ, Heymsfield SB, et al. One-year health-related quality of life outcomes in weight loss trial participants: comparison of three measures. Health Qual Life Outcomes 2009;7:53.

65. Tessier A, Mayo NE, Cieza A. Content identification of the IWQOL-Lite with the International Classification of Functioning, Disability and Health. Qual Life Res 2011;20: 467-477.

66. Duval K, Marceau P, Pérusse L, Lacasse Y. An overview of obesity-specific quality of life questionnaires. Obes Rev 2006; 7:347-360.

67. Haidar Y, Cosman B. Obesity epidemiology. Clin Colon Rectal Surg 2011;24:205-210.

68. Camden, S. Obesity: an emerging concern for patients and nurses. OJIN 2009;14:Manuscript 1.

Address correspondence to: Roberto Accardi, RN, MSC, PhD Department of Surgery

Fondazione IRCCS Ca' Granda Ospedale Maggiore Policlinico

Via Francesco Sforza 35 20121 Milan Italy

E-mail: roberto.accardi@policlinico.mi.it 


\section{AUTHOR QUERY FOR BARI-2017-0015-VER9-ACCARDI_1P}

AU1: Please review all authors' surnames for accurate indexing citations.

AU2: Please mention the academic degrees of the author "Antonella Delle Fave."

AU3: Please check the correctness of authors' affiliations.

AU4: Author Disclosure accurate? If not, please amend as needed.

AU5: Please check the publication year, volume number, and page range of Ref. 26.

AU6: Please confirm the address of correspondence. 